\title{
PRRT2 Mutations Are Related to Febrile Seizures in Epileptic Patients
}

\section{Zheng-Wen He ${ }^{1, \dagger}$, Jian Qu ${ }^{2, \dagger}$, Ying Zhang ${ }^{2}$, Chen-Xue Mao ${ }^{2}$, Zhi-Bin Wang ${ }^{2}$, Xiao-Yuan Mao ${ }^{2}$, Zhi-Yong Deng ${ }^{1}$, Bo-Ting Zhou ${ }^{3}$, Ji-Ye Yin ${ }^{2}$, Hong-Yu Long ${ }^{4}$, Bo Xiao ${ }^{4}$, Yu Zhang ${ }^{2}$, Hong-Hao Zhou ${ }^{2}$ and Zhao-Qian Liu ${ }^{2, *}$}

1 Department of Neurosurgery, the Affiliated Cancer Hospital of Xiangya School of Medicine, Central South University, Changsha 410014, China; E-Mails: hezhengw@gmail.com (Z.-W.H.); dzyong111@gmail.com (Z.-Y.D.)

2 Department of Clinical Pharmacology, Xiangya Hospital, Central South University, Changsha 410008, China; E-Mails: seemore126@gmail.com (J.Q.); yz_fly@csu.edu.cn (Y.Z.); sharemix@csu.edu.cn (C.-X.M.); wangzhibinup@gmail.com (Z.-B.W.); xiaoyuanm@csu.edu.cn (X.-Y.M.); yinjiye@csu.edu.cn (J.-Y.Y.); zbtinggggg@gmail.com (Y.Z.); honghaozhou2012@gmail.com (H.-H.Z.)

3 Institute of Clinical Pharmacology, Central South University, Hunan Key Laboratory of Pharmacogenetics, Changsha 410078, China; E-Mail: botingzhou0918@gmail.com

4 Departments of Pharmacy and Neurology, Xiangya Hospital, Central South University, Changsha 410008, China; E-Mails: longhongyu@csu.edu.cn (H.-Y.L.);

boxiaoxiao123@gmail.com (B.X.)

$\dagger$ These authors contributed equally to this work.

* Author to whom correspondence should be addressed; E-Mail: zqliu@mail.csu.edu.cn; Tel.: +86-731-8480-5380; Fax: +86-731-8235-4476.

External Editor: Sabrina Angelini

Received: 29 October 2014; in revised form: 2 December 2014 / Accepted: 10 December 2014 / Published: 16 December 2014

Abstract: Previous studies reported that the proline-rich transmembrane protein 2
(PRRT2) gene was identified to be related to paroxysmal kinesigenic dyskinesia (PKD),
infantile convulsions with PKD, PKD with migraine and benign familial infantile epilepsy
(BFIE). The present study explores whether the PRRT2 mutation is a potential cause
of febrile seizures, including febrile seizures plus (FS+), generalized epilepsy with febrile
seizures plus (GEFS+) and Dravet syndrome (DS); thus, it may provide a new drug target 
for personalized medicine for febrile seizure patients. We screened PRRT2 exons in a cohort of 136 epileptic patients with febrile seizures, including FS+, GEFS+ and DS. PRRT2 genetic mutations were identified in 25 out of $136(18.4 \%)$ febrile seizures in epileptic patients. Five loss-of-function and coding missense mutations were identified: c.649delC (p.R217Efs*12), c.649_650insC (p.R217Pfs*8), c.412C >G (p.Pro138Ala), c.439G $>$ C (p.Asp147His) and c.623C $>$ A (p.Ser208Tyr). PRRT2 variants were probably involved in the etiology of febrile seizures in epileptic patients.

Keywords: proline-rich transmembrane protein 2; febrile seizures; mutation; epilepsy

\section{Introduction}

There is a long-known relationship between human epilepsies and other paroxysmal brain disorders, such as paroxysmal dyskinesia, episodic ataxia or migraine. They are all involuntary movements, which are spontaneous or triggered by various types of stimuli [1]. Several previous research studies described proline-rich transmembrane protein 2 (PRRT2) as the causative gene in some nervous system diseases, including paroxysmal kinesigenic dyskinesia (PKD), infantile convulsions with PKD, benign familial infantile epilepsy (BFIE), hemiplegic migraine and episodic ataxia alone [1-13]. Evidence for shared pathophysiologic mechanisms underlying the concurrence of benign infantile convulsions (IC) and of PKD in the same patients or families was obtained [8,13]. PRRT2 gene consists of four exons, encoding proline-rich transmembrane protein 2, and maps to chromosome 16p11.2, one of the known BFIE loci $[2,14]$. The PRRT2 protein is highly expressed in the developing nervous system and localized in the axons [6]. Although its interaction with synaptosomal-associated protein 25 (SNAP25) suggests important roles in synaptic vesicle docking and exocytosis, the function of the PRRT2 gene is poorly understood $[2,14,15]$. Most of the pathological mutations in the PRRT2 gene discovered cause truncation of the protein, leading to loss of function. Among mutations in PRRT2, c.649dupC has been shown to be a mutation hotspot recently [9,14-22]. Some studies on PRRT2 mutations in a small number of atypical benign familial and infantile epilepsies [9,14,15] provided evidence of the association between febrile seizures or childhood absence seizures and PRRT2 mutations; however, the presence of PRRT2 mutations in a broader spectrum of epileptic phenotypes has not been investigated clearly.

In this study, we aim to widen the spectrum of phenotypes associated with PRRT2 mutations and investigate whether PRRT2 mutations are involved in febrile seizure-related epilepsy, including febrile seizures plus (FS+), generalized epilepsy with febrile seizures plus (GEFS+) and Dravet syndrome (DS).

\section{Results and Discussion}

Two truncating frameshift mutations and three missense mutations in 136 patients with febrile seizure-related epilepsy were identified by sequencing of the PRRT2 gene (Figure 1). Among these mutations, p.Arg217Glufs*12 (c.649delC) was found in two patients (one FS+, one DS); p.R217Pfs*8 
(c.640_641insC) was found in four patients (two FS+, one GEFS+, one DS); c.412C $>$ G (p.Pro138Ala) was found in 14 patients (eight FS+, two GEFS+, four DS); c.439G $>$ C (p.Asp147His) was found in five patients (four GEFS+, one DS); and c.623C >A (p.Ser208Tyr) was found in one DS patient. None of these mutations were found in 108 healthy Chinese controls. The characteristics of 25 mutated patients are shown in Table 1.

Figure 1. The identified proline-rich transmembrane protein 2 (PRRT2) mutations in epileptic patients with febrile seizures. (A) c.649_650insC (p.R217Pfs*8); (B) c.649delC (p.R217Efs*12); (C) c.412C >G (p.Pro138Ala); (D) c.439G >C (p.Asp147His) and (E) c.623C >A (p.Ser208Tyr).

A c.649_650insC (p.R217Pfs*8)

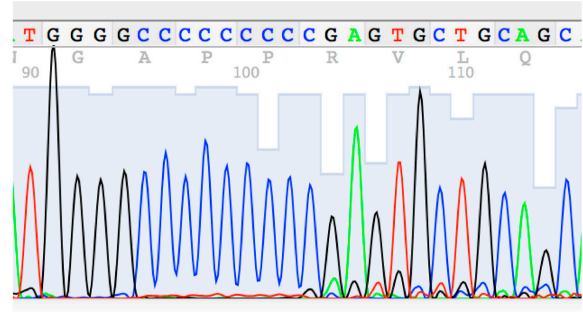

Normal strand

C c.412C >G (p.Pro138Ala)

AGCCCCAGAGC TG C TCCCCAAC CA

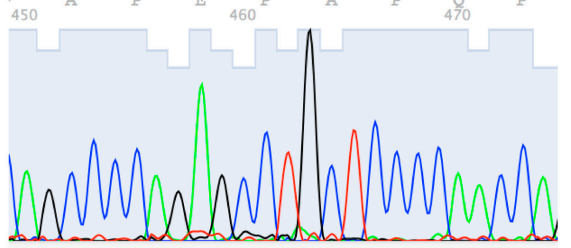

Normal strand

A G C C C CAGAG C C T G C T C C C CAAC C A

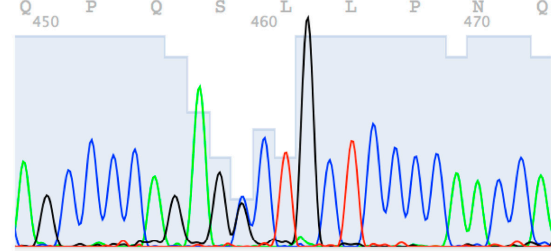

c. $412 \mathrm{C}>\mathrm{G}$

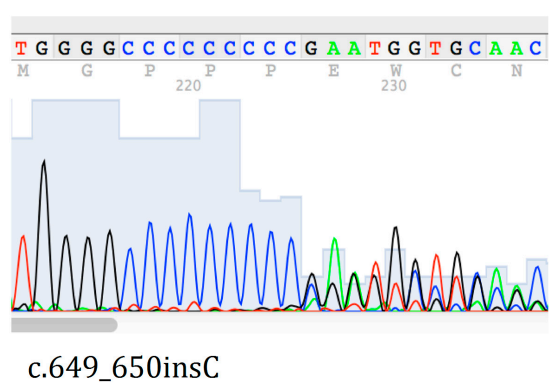

D c.439G $>$ C (p.Asp147His)

$\underset{D}{A}$ C C C C C G G C CAGA A T C C CA G C C :

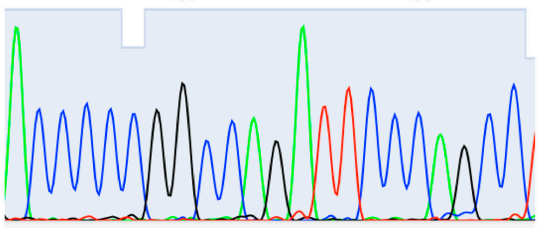

Normal strand
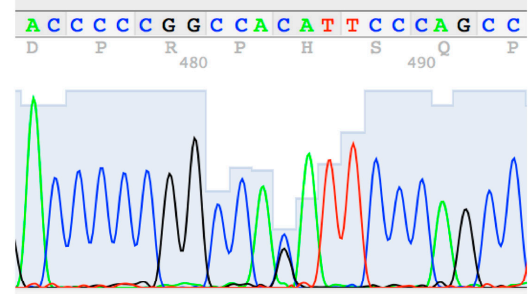

c. $439 \mathrm{G}>\mathrm{C}$
B c.649delC (p.R217Efs*12)

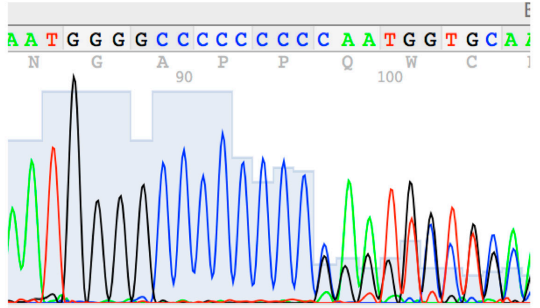

c.649delC

E c.623C >A (p.Ser208Tyr)

T CAAAAAAATC C C C C C CA

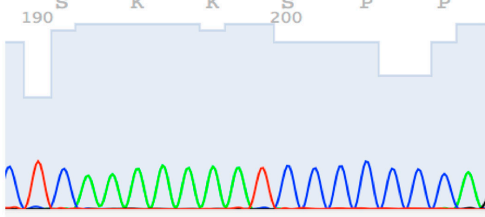

Normal strand

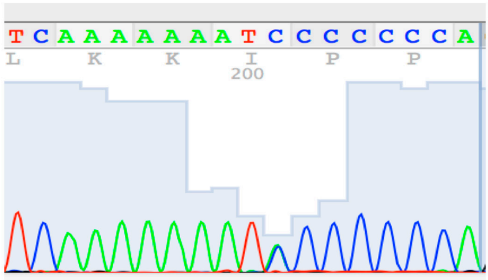

c. $623 \mathrm{C}>\mathrm{A}$ 
Table 1. Characteristics of PRRT2 mutations in epileptic patients with febrile seizures. M, male; F, female; d, days; w, weeks; m, months; y, years; FS+, febrile seizures plus; GEFS+, generalized epilepsy with febrile seizures plus; DS, Dravet syndrome; N, normal; ND, not done; AB, abnormal; CBZ, carbamazepine; PHT, phenytoin; OXC, oxcarbazepine; VPA, sodium valproate; LEV, levetiracetam; TPM, topiramate; $\mathrm{PB}$, phenobarbitone. All patients had heterozygous mutations.

\begin{tabular}{|c|c|c|c|c|c|c|c|c|c|c|c|}
\hline $\begin{array}{c}\text { Case } \\
\text { Number }\end{array}$ & Gender & $\begin{array}{c}\text { Age } \\
\text { (year) }\end{array}$ & $\begin{array}{l}\text { Age at } \\
\text { Onset }\end{array}$ & Subtypes & Familial/Sporadic & GGE/MRI/CT & $\begin{array}{c}\text { Duration } \\
\text { of Seizure }\end{array}$ & $\begin{array}{c}\text { Frequency } \\
\text { of Seizure }\end{array}$ & $\begin{array}{c}\text { Current } \\
\text { Medication }\end{array}$ & $\begin{array}{c}\text { Nucleotide } \\
\text { Changes }\end{array}$ & $\begin{array}{c}\text { Amino Acid } \\
\text { Changes }\end{array}$ \\
\hline 89 & $M$ & 7 & $2 y$ & FS + & Sporadic & $\mathrm{N} / \mathrm{N} / \mathrm{N}$ & $<20 \mathrm{~s}$ & $1-2 \mathrm{~m}$ & $\mathrm{CBZ}$ & c. $412 \mathrm{C}>\mathrm{G}$ & p.Pro138Ala \\
\hline 123 & $\mathrm{~F}$ & 18 & $13 \mathrm{y}$ & FS + & Sporadic & $\mathrm{N} / \mathrm{N} / \mathrm{ND}$ & $5-10 \mathrm{~s}$ & $1-2 \mathrm{~m}$ & VPA & c. $623 \mathrm{C}>\mathrm{A}$ & p.Ser208Tyr \\
\hline 174 & M & 16 & $2 \mathrm{y}$ & FS+ & Sporadic & $\mathrm{AB} / \mathrm{N} / \mathrm{N}$ & $<30 \mathrm{~s}$ & $4-5 \mathrm{~m}$ & CBZ, PB & c. $412 \mathrm{C}>\mathrm{G}$ & p.Pro138Ala \\
\hline 114 & M & 6 & $2 y$ & $\mathrm{FS}+$ & Sporadic & $\mathrm{N} / \mathrm{ND} / \mathrm{N}$ & $1 \mathrm{~min}$ & $10-15 \mathrm{y}$ & $\mathrm{CBZ}$ & c. $412 \mathrm{C}>\mathrm{G}$ & p.Pro138Ala \\
\hline 192 & M & 13 & $1 \mathrm{y}$ & FS + & Sporadic & $\mathrm{N} / \mathrm{AB} / \mathrm{N}$ & $10 \mathrm{~s}$ & $2-3 y$ & VPA, LTG & c. $439 \mathrm{G}>\mathrm{C}$ & p.Asp147His \\
\hline 311 & M & 6 & $4 y$ & FS+ & Sporadic & $\mathrm{AB} / \mathrm{N} / \mathrm{N}$ & $3-5 \mathrm{~min}$ & $3-5 \mathrm{~m}$ & LEV & c. $412 \mathrm{C}>\mathrm{G}$ & p.Pro138Ala \\
\hline 313 & M & 6 & $3 y$ & FS+ & Sporadic & $\mathrm{N} / \mathrm{N} / \mathrm{N}$ & $10 \mathrm{~s}$ & $2-4 \mathrm{~m}$ & VPA, PHT & c. $412 \mathrm{C}>\mathrm{G}$ & p.Pro138Ala \\
\hline SN540 & M & 18 & $5 \mathrm{~m}$ & DS & Familial & $\mathrm{AB} / \mathrm{ND} / \mathrm{ND}$ & $1-2 \min$ & $1-2 \mathrm{~m}$ & CBZ, OXC & c.640_641insC & p.R217Pfs*8 \\
\hline 363 & M & 33 & $9 y$ & FS + & Sporadic & $\mathrm{AB} / \mathrm{N} / \mathrm{N}$ & $3-10 \mathrm{~s}$ & $1 \mathrm{~m}$ & CBZ,PHT & $\begin{array}{c}\text { c. } 640 \_641 \mathrm{ins} C \\
\text { c. } 439 \mathrm{G}>\mathrm{C}\end{array}$ & $\begin{array}{l}\text { p.R217Pfs*8 } \\
\text { p.Asp147His }\end{array}$ \\
\hline 737 & M & 7 & $4 y$ & FS + & Sporadic & $\mathrm{N} / \mathrm{ND} / \mathrm{N}$ & $2-5 \mathrm{~s}$ & $2 \mathrm{~m}$ & VPA & c. $412 \mathrm{C}>\mathrm{G}$ & p.Pro138Ala \\
\hline 853 & M & 17 & $8 y$ & $\mathrm{FS}+$ & Sporadic & $\mathrm{N} / \mathrm{ND} / \mathrm{ND}$ & $2-5 \min$ & $4-8 y$ & $\mathrm{CBZ}$ & c. $412 \mathrm{C}>\mathrm{G}$ & p.Pro138Ala \\
\hline HH69 & M & 15 & $3 y$ & FS + & Sporadic & N/N/AB & $1 \mathrm{~min}$ & $1-2 \mathrm{~m}$ & VPA & c. $439 \mathrm{G}>\mathrm{C}$ & p.Asp147His \\
\hline SN252 & M & 24 & $4 \mathrm{y}$ & FS + & Sporadic & $\mathrm{AB} / \mathrm{N} / \mathrm{N}$ & $2 \min$ & $2-3$ y & $\mathrm{CBZ}, \mathrm{VPA}$ & c. $439 \mathrm{G}>\mathrm{C}$ & p.Asp147His \\
\hline SN488 & $\mathrm{F}$ & 20 & $13 \mathrm{y}$ & FS + & Sporadic & $\mathrm{AB} / \mathrm{N} / \mathrm{N}$ & $2-3 \min$ & $2-3 \mathrm{~m}$ & VPA, TPM & c. $412 \mathrm{C}>\mathrm{G}$ & p.Pro138Ala \\
\hline SN275 & $\mathrm{F}$ & 12 & $3 y$ & $\mathrm{FS}+$ & Sporadic & $\mathrm{AB} / \mathrm{N} / \mathrm{N}$ & $2-4 \min$ & $1-2 y$ & $\mathrm{CBZ}$ & c. $649 \mathrm{delC}$ & p.Arg217Glufs*12 \\
\hline 812 & M & 32 & $10 \mathrm{y}$ & GEFS + & Familial & $\mathrm{N} / \mathrm{ND} / \mathrm{ND}$ & $5-6 \min$ & $4-6 \mathrm{~d}$ & $\mathrm{CBZ}$ & c. $412 \mathrm{C}>\mathrm{G}$ & p.Pro138Ala \\
\hline 1232 & M & 15 & $2 \mathrm{y}$ & GEFS+ & Familial & $\mathrm{N} / \mathrm{ND} / \mathrm{N}$ & $1-3 \mathrm{~min}$ & $2 w$ & VPA & c. $412 \mathrm{C}>\mathrm{G}$ & p.Pro138Ala \\
\hline SN854 & M & 36 & $8 \mathrm{y}$ & GEFS+ & Familial & $\mathrm{N} / \mathrm{ND} / \mathrm{ND}$ & $1-2 \mathrm{~min}$ & $2 \mathrm{~d}$ & CBZ, PB & c.640_641insC & p.R217Pfs*8 \\
\hline 576 & $\mathrm{~F}$ & 5 & $5 \mathrm{~m}$ & DS & Sporadic & $\mathrm{N} / \mathrm{ND} / \mathrm{N}$ & $1 \mathrm{~min}$ & $10 \mathrm{w}$ & CBZ, VPA & c. $439 \mathrm{G}>\mathrm{C}$ & p.Asp147His \\
\hline 1186 & $\mathrm{~F}$ & 10 & $8 \mathrm{~m}$ & DS & Sporadic & $\mathrm{N} / \mathrm{N} / \mathrm{ND}$ & $1-3 \mathrm{~min}$ & $2-3 \mathrm{w}$ & CBZ, VPA & c. $412 \mathrm{C}>\mathrm{G}$ & p.Pro138Ala \\
\hline 872 & $\mathrm{~F}$ & 3 & $9 \mathrm{~m}$ & DS & Sporadic & $\mathrm{AB} / \mathrm{N} / \mathrm{N}$ & $10 \mathrm{~min}$ & $1 \mathrm{w}$ & CBZ, LEV & c. $412 \mathrm{C}>\mathrm{G}$ & p.Pro138Ala \\
\hline SN676 & $\mathrm{M}$ & 32 & $5 \mathrm{~m}$ & DS & Sporadic & $\mathrm{N} / \mathrm{ND} / \mathrm{ND}$ & $2-3 \mathrm{~min}$ & $2-3 \mathrm{~d}$ & OXC, VPA & c. $649 \mathrm{delC}$ & p.Arg217Glufs*12 \\
\hline
\end{tabular}


Table 1. Cont.

\begin{tabular}{|c|c|c|c|c|c|c|c|c|c|c|c|}
\hline $\begin{array}{c}\text { Case } \\
\text { Number }\end{array}$ & Gender & $\begin{array}{c}\text { Age } \\
\text { (year) }\end{array}$ & $\begin{array}{c}\text { Age at } \\
\text { Onset } \\
\end{array}$ & Subtypes & Familial/Sporadic & GGE/MRI/CT & $\begin{array}{c}\text { Duration } \\
\text { of Seizure }\end{array}$ & $\begin{array}{r}\text { Frequency } \\
\text { of Seizure }\end{array}$ & $\begin{array}{c}\text { Current } \\
\text { Medication } \\
\end{array}$ & $\begin{array}{c}\text { Nucleotide } \\
\text { Changes }\end{array}$ & $\begin{array}{c}\text { Amino Acid } \\
\text { Changes }\end{array}$ \\
\hline SN740 & $\mathrm{F}$ & 25 & $40 \mathrm{~d}$ & DS & Sporadic & $\mathrm{AB} / \mathrm{N} / \mathrm{N}$ & $1-2 \min$ & $3 \mathrm{~m}$ & CBZ, VPA & c. $412 \mathrm{C}>\mathrm{G}$ & p.Pro138Ala \\
\hline SN540 & $\mathrm{M}$ & 18 & $5 \mathrm{~m}$ & DS & Familial & $\mathrm{AB} / \mathrm{N} / \mathrm{N}$ & $1-2 \min$ & $1-2 \mathrm{~m}$ & $\mathrm{CBZ}, \mathrm{OXC}$ & c.640_641insC & p.R217Pfs*8 \\
\hline 428 & $\mathrm{M}$ & 12 & $11 \mathrm{~m}$ & $\mathrm{DS}$ & Sporadic & $\mathrm{AB} / \mathrm{ND} / \mathrm{N}$ & $1 \mathrm{~min}$ & $1-2 \mathrm{w}$ & LEV, VPA & c. $412 \mathrm{C}>\mathrm{G}$ & p.Pro138Ala \\
\hline
\end{tabular}


p.R217Pfs*8 (c.640_641insC) was the common mutation in benign familial infantile epilepsy (BFIE), infantile convulsions and choreoathetosis (ICCA) and PKD [1,2,4,8,9,14,23]. We also found that two FS+ patients, one GEFS + patient and one DS patient have this mutation. p.Arg217Glufs*12 (c.649delC) was found in two patients. Moreover, three missense mutations were found in the dbSNP database and were designated as rs79182085 (c.412C > G), rs79568162 (c.439G>C) and rs201409113 (c.623C $>$ A). SIFT [24] predicted the first two variants to be "tolerated" and the last variant as "damaging". PholyPhen [25] classified the first two variants as "benign" and the last variant as "probably damaging". However, the performance of these prediction programs on the wild-type residues of variation sites is known to be low [26]. The allelic frequencies of these three SNPs in our cohort were $0.051,0.018$ and 0.0036 , respectively. Rs79182085 allelic frequency is 0.158 in dbSNP in the Chinese and Japanese population. Frequency data for the other two SNPs are not available in dbSNP. Moreover, these five mutations were not found in our healthy controls.

PRRT2 is a transmembrane protein that is capable of binding to SNAP25 [2]. Most of the pathological mutations in the PRRT2 gene that have been discovered to date cause truncation of the protein, leading to loss of function [14,27]. A previous study has elucidated the role of PRRT2 mutations in BFIE and provided evidence of associations with febrile seizures and childhood absence seizures [4]. Ingrid Scheffer and colleagues screened out eight individuals with PRRT2 mutations exhibiting febrile seizures or febrile seizures plus [9]. However, some studies found no mutations in epileptic encephalopathies and benign and severe infantile seizures [16,28]. In the current study, we found some truncating frameshift mutations and missense mutations presenting in the febrile seizure-related epileptic patients. Although the mutations were not as common as in PKD and BFIE patients, especially the hotspot mutation c.649_650insC (p.P217fsX7), this still suggests that the PRRT2 gene mutant in febrile seizures is related to epilepsy, including FS+, GEFS+ and DS.

\section{Experimental Section}

\subsection{Subjects}

One hundred thirty six patients with fever-related epilepsy (74 FS+, 34 GEFS+ and 28 DS) and 108 matched healthy controls from Xiangya hospital and the Second Xiangya Hospital of Central South University were recruited in this study. The healthy controls were randomly selected from the people coming to the hospital for physical examination without any illness, and they were matched with patient groups. The diagnostic criteria were defined according to the international classification [29,30]. Informed consent was obtained from all patients or their parents to participate in the study. The Ethics Committee of Xiangya School of Medicine and the Ethics Committee of Institute of Clinical Pharmacology of Central South University approved the study. The clinical study admission (Registration Number: ChiCTR-TCH-0000813, date of approval: 29 April 2010 04/29/2010) was approved by the Chinese Clinical Trial Register. All patients consented to their data being used for research. 


\subsection{Mutation Analysis of the Proline-Rich Transmembrane Protein 2 (PRRT2) Gene}

DNA was extracted from whole blood according to previous standard procedures [31]. All PRRT2 gene coding exons were screened for mutations by PCR amplification and Sanger sequencing. Primers for mutational analysis of all PRRT2 gene coding exons were followed as previously described (Table 2) [23].

Table 2. Primer sequences of the PRRT2 gene. Exon 2A: PRRT2 gene exon 2 fragment A; Exon2B: PRRT2 gene exon 2 fragment B; Exon3-4: PRRT2 gene exon 3 and exon 4.

\begin{tabular}{ccc}
\hline PRRT2 & Forward Primer & Reverse Primer \\
\hline Exon $2 A$ & 5'-ctcctcctcttccagggttt-3' & 5'-tttttgagggtggtgagtga-3' \\
Exon $2 B$ & 5'-tctgagagtgtaggggaaaagc-3' & 5'-ctagggagaggcaaacaaagg-3' \\
Exon3-4 & 5'-tccacctgatcccttctgg-3' & 5'-caggctcccttggtccttag-3' \\
\hline
\end{tabular}

\section{Conclusions}

Nowadays, although more and more research has been focused on the susceptibility and drug efficacy of epilepsy, there are still some patients who cannot benefit from the anti-epileptic drug efficacy. The susceptibility genes as drug targets play a key role in the optimization of treatment. As a new susceptibility gene of epileptic patients with febrile seizures, mutations of PRRT2 might underlie a broader range of seizure subtypes than what was previously suspected. Overall, PRRT2 mutations were probably involved in the etiology of febrile seizure-related epilepsy. As a new susceptibility gene, the PRRT2 gene may provide a new drug target for personalized medicine for febrile seizure patients.

\section{Acknowledgments}

We thank the study participants and the support from the grants of the National High-tech R\&D Program of China (863 Program) (2012AA02A517), the National Natural Science Foundation of China $(81173129,81202595,81373490)$, the Special Scientific Research Foundation of Doctor Disciplines in University of Ministry of Education of China (20110162110034), the Hunan Provincial Natural Science Foundation of China (12JJ7006) and the Hunan Provincial Innovation Foundation for Postgraduates (CX2013B102).

\section{Author Contributions}

Ideas and experiment design: Zheng-Wen He, Jian Qu, Zhao-Qian Liu. Sample collection: Ying Zhang, Chen-Xue Mao, Zhi-Bin Wang, Hong-Yu Long, Bo Xiao, Yu Zhang. Lab work: Jian Qu, Zhi-Yong Deng, Bo-Ting Zhou. Analysis and data interpretation: Xiao-Yuan Mao, Ji-Ye Yin. Writing and review of the manuscript: all of the authors. Study supervision: Hong-Hao Zhou, Zhao-Qian Liu.

\section{Conflicts of Interest}

The authors declare no conflict of interest. 


\section{References}

1. Gardiner, A.R.; Bhatia, K.P.; Stamelou, M.; Dale, R.C.; Kurian, M.A.; Schneider, S.A.; Wali, G.M.; Counihan, T.; Schapira, A.H.; Spacey, S.D.; et al. PRRT2 gene mutations from paroxysmal dyskinesia to episodic ataxia and hemiplegic migraine. Neurology 2012, 79, 2115-2121.

2. Chen, W.J.; Lin, Y.; Xiong, Z.Q.; Wei, W.; Ni, W.; Tan, G.H.; Guo, S.L.; He, J.; Chen, Y.F.; Zhang, Q.J.; et al. Exome sequencing identifies truncating mutations in PRRT2 that cause paroxysmal kinesigenic dyskinesia. Nat. Genet. 2011, 43, 1252-1255.

3. Cloarec, R.; Bruneau, N.; Rudolf, G.; Massacrier, A.; Salmi, M.; Bataillard, M.; Boulay, C.; Caraballo, R.; Fejerman, N.; Genton, P.; et al. PRRT2 links infantile convulsions and paroxysmal dyskinesia with migraine. Neurology 2012, 79, 2097-2103.

4. De Vries, B.; Callenbach, P.M.C.; Kamphorst, J.T.; Weller, C.M.; Koelewijn, S.C.; ten Houten, R.; de Coo, I.F.M.; Brouwer, O.F.; van den Maagdenberg, A.M.J.M. PRRT2 mutation causes benign familial infantile convulsions. Neurology 2012, 79, 2154-2155.

5. Friedman, J.; Olvera, J.; Silhavy, J.L.; Gabriel, S.B.; Gleeson, J.G. Mild paroxysmal kinesigenic dyskinesia caused by PRRT2 missense mutation with reduced penetrance. Neurology 2012, 79, 946-948.

6. Lee, H.Y.; Huang, Y.; Bruneau, N.; Roll, P.; Roberson, E.D.O.; Hermann, M.; Quinn, E.; Maas, J.; Edwards, R.; Ashizawa, T.; et al. Mutations in the gene PRRT2 cause paroxysmal kinesigenic dyskinesia with infantile convulsions. Cell Rep. 2012, 1, 2-12.

7. Marini, C.; Conti, V.; Mei, D.; Battaglia, D.; Lettori, D.; Losito, E.; Bruccini, G.; Tortorella, G.; Guerrini, R. PRRT2 mutations in familial infantile seizures, paroxysmal dyskinesia, and hemiplegic migraine. Neurology 2012, 79, 2109-2114.

8. Rochette, J.; Roll, P.; Szepetowski, P. Genetics of infantile seizures with paroxysmal dyskinesia: The infantile convulsions and choreoathetosis (ICCA) and icca-related syndromes. J. Med. Genet. 2008, 45, 773-779.

9. Scheffer, I.E.; Grinton, B.E.; Heron, S.E.; Kivity, S.; Afawi, Z.; Iona, X.; Goldberg-Stern, H.; Kinali, M.; Andrews, I.; Guerrini, R.; et al. PRRT2 phenotypic spectrum includes sporadic and fever-related infantile seizures. Neurology 2012, 79, 2104-2108.

10. Wang, J.L.; Cao, L.; Li, X.H.; Hu, Z.M.; Li, J.D.; Zhang, J.G.; Liang, Y.; San-A; Li, N.; Chen, S.Q.; et al. Identification of PRRT2 as the causative gene of paroxysmal kinesigenic dyskinesias. Brain 2011, 134, 3490-3498.

11. Wang, J.L.; Mao, X.; Hu, Z.M.; Li, J.D.; Li, N.; Guo, J.F.; Jiang, H.; Shen, L.; Li, J.; Shi, Y.T.; et al. Mutation analysis of PRRT2 in two chinese BFIS families and nomenclature of PRRT2 related paroxysmal diseases. Neurosci. Lett. 2013, 552, 40-45.

12. Wang, K.; Zhao, X.Y.; Du, Y.; He, F.P.; Peng, G.P.; Luo, B.Y. Phenotypic overlap among paroxysmal dyskinesia subtypes: Lesson from a family with PRRT2 gene mutation. Brain Dev. Jpn. 2013, 35, 664-666.

13. Rochette, J.; Roll, P.; Fu, Y.H.; Lemoing, A.G.; Royer, B.; Roubertie, A.; Berquin, P.; Motte, J.; Wong, S.W.; Hunter, A.; et al. Novel familial cases of ICCA (infantile convulsions with paroxysmal choreoathetosis) syndrome. Epileptic Disord. 2010, 12, 199-204. 
14. Schubert, J.; Paravidino, R.; Becker, F.; Berger, A.; Bebek, N.; Bianchi, A.; Brockmann, K.; Capovilla, G.; Bernardina, B.D.; Fukuyama, Y.; et al. PRRT2 mutations are the major cause of benign familial infantile seizures. Hum. Mutat. 2012, 33, 1439-1443.

15. Schmidt, A.; Kumar, K.R.; Redyk, K.; Grunewald, A.; Leben, M.; Munchau, A.; Sue, C.M.; Hagenah, J.; Hartmann, H.; Lohmann, K.; et al. Two faces of the same coin: Benign familial infantile seizures and paroxysmal kinesigenic dyskinesia caused by PRRT2 mutations. Arch. Neurol. 2012, 69, 668-670.

16. Djemie, T.; Weckhuysen, S.; Holmgren, P.; Hardies, K.; van Dyck, T.; Hendrickx, R.; Schoonjans, A.S.; van Paesschen, W.; Jansen, A.C.; de Meirleir, L.; et al. PRRT2 mutations: Exploring the phenotypical boundaries. J. Neurol. Neurosurg. Psychiatry 2014, 85, 462-465.

17. Igarashi, A.; Okumura, A.; Shimada, S.; Shimojima, K.; Abe, S.; Ikeno, M.; Shimizu, T.; Yamamoto, T. Phenotype of patients with a common c.649_650c PRRT2 mutation. Epilepsia 2013, 54, 198-198.

18. Jing, X.Y.; Li, X.H.; Yuan, P.; Deng, J.; Hu, B.; Wang, Y.M. A novel mutation and functional implications of 5 variants in the PRRT2 gene in 20 paroxysmal kinesigenic dyskinesia pedigrees. Parkinsonism Relat. Disord. 2013, 19, 639-642.

19. Labate, A.; Tarantino, P.; Viri, M.; Mumoli, L.; Gagliardi, M.; Romeo, A.; Zara, F.; Annesi, G.; Gambardella, A. Homozygous c.649dupc mutation in PRRT2 worsens the BFIS/PKD phenotype with mental retardation, episodic ataxia, and absences. Epilepsia 2012, 53, e196-e199.

20. Li, H.F.; Ni, W.; Xiong, Z.Q.; Xu, J.F.; Wu, Z.Y. PRRT2 c.649dupc mutation derived from de novo in paroxysmal kinesigenic dyskinesia. CNS Neurosc. Ther. 2013, 19, 61-65.

21. Yang, X.; Zhang, Y.; Xu, X.; Wang, S.; Yang, Z.; Wu, Y.; Liu, X.; Wu, X. Phenotypes and PRRT2 mutations in chinese families with benign familial infantile epilepsy and infantile convulsions with paroxysmal choreoathetosis. BMC Neurol. 2013, 13, 209.

22. Youn, J.; Jeong, Y.; Ahn, J.Y.; Cho, J.W. PRRT2 gene mutation analysis in korean familial and sporadic patients with paroxysmal kinesigenic dyskinesia. Mov. Disord. 2013, 28, S401-S401.

23. Lee, Y.C.; Lee, M.J.; Yu, H.Y.; Chen, C.; Hsu, C.H.; Lin, K.P.; Liao, K.K.; Chang, M.H.; Liao, Y.C.; Soong, B.W. PRRT2 mutations in paroxysmal kinesigenic dyskinesia with infantile convulsions in a taiwanese cohort. PLoS One 2012, 7, e38543.

24. Sift. Available online: http://sift.Jcvi.Org/ (accessed on 1 August 2014).

25. Polyphen SNP Data Collection. Available online: http://genetics.Bwh.Harvard.Edu/pph/data/ (accessed on 1 August 2014).

26. Ali, H.; Urolagin, S.; Gurarslan, O.; Vihinen, M. Performance of protein disorder prediction programs on amino acid substitutions. Hum. Mutat. 2014, 35, 794-804.

27. Palamara, G.; Labate, A.; Mumoli, L.; Tarantino, P.; Ferlazzo, E.; Fratto, A.; Pantusa, M.; Annesi, G.; Aguglia, U.; Gambardella, A. Mutations in PRRT2 result in familial infantile seizures with heterogeneous phenotypes including febrile convulsions and probable sudep. Epilepsia 2013, 54, 194-194.

28. Heron, S.E.; Ong, Y.S.; Yendle, S.C.; McMahon, J.M.; Berkovic, S.F.; Scheffer, I.E.; Dibbens, L.M. Mutations in PRRT2 are not a common cause of infantile epileptic encephalopathies. Epilepsia 2013, 54, e86-e89. 
29. Commission on Classification and Terminology of the International League against Epilepsy. Proposal for revised classification of epilepsies and epileptic syndromes. Epilepsia 1989, 30, 389-399.

30. Berg, A.T.; Scheffer, I.E. New concepts in classification of the epilepsies: Entering the 21st century. Epilepsia 2011, 52, 1058-1062.

31. Qu, J.; Zhou, B.T.; Yin, J.Y.; Xu, X.J.; Zhao, Y.C.; Lei, G.H.; Tang, Q.; Zhou, H.H.; Liu, Z.Q. $A B C C 2$ polymorphisms and haplotype are associated with drug resistance in chinese epileptic patients. CNS Neurosci. Ther. 2012, 18, 647-651.

(C) 2014 by the authors; licensee MDPI, Basel, Switzerland. This article is an open access article distributed under the terms and conditions of the Creative Commons Attribution license (http://creativecommons.org/licenses/by/4.0/). 